\title{
Utilização da Metaheurística na Detecção de Aglomerados Espaciais de Fasciola Hepática em Bovinos no Sul do Espírito Santo
}

\author{
Wagner S. Tassinari ${ }^{1,2,3} \quad$ Marcelo Dib $^{1} \quad \underline{\text { Bruna A. Santiago }}^{2^{*}}$ \\ Universidade Federal Rural do Rio de Janeiro \\ ${ }^{1}$ Departamento de Matemática \\ ${ }^{2}$ Programa de Pós-Graduação em Modelagem Matemática e Computacional \\ ${ }^{3}$ Pós- graduação em Ciências Veterinárias \\ BR-465, Km 7 Seropédica - RJ. CEP 23890-00 \\ E-mail: brunak11@ hotmail.com
}

\author{
Isabela Martins \\ Universidade Federal do Espírito Santo - Centro de Ciências Agrárias \\ 29500-00, Campus Alegre, Alegre, ES \\ E-mail: isabella.martins@ufes.br
}

\begin{abstract}
RESUMO
A fasciolose é uma doença causada pelo parasito Fasciola hepatica, trematoda que parasita o fígado e as vias biliares de bovinos e ovinos, mas diagnosticada também em caprinos, equinos, búfalos, humanos e animais silvestres, como a capivara e ratão do banhado. A ocorrência desta parasitose está ligada a presença de moluscos do gênero Lymnaea, hospedeiro intermediário, bem como de hospedeiros definitivos parasitados (ovinos e bovinos principalmente), os quais são disseminadores de ovos [2]. Além disso, presença de áreas alagadas favorece a manutenção do ciclo do parasito por ser ambiente adequado para o desenvolvimento do molusco [1].

A fasciolose encontra-se em ampla distribuição mundial e a sua dispersão geográfica vêm aumentando com o passar dos anos devido à transferência de animais parasitados de locais onde a doença é enzoótica para localidades indenes [2].

Nos Estados de Minas Gerais, Goiás, Bahia e Espírito Santo estão surgindo novas áreas de ocorrência de F. hepática, caracterizadas pela presença dos hospedeiros intermediários e vertebrados naturalmente infectados. Bernardo et al. (2011) [1] registraram prevalências de fígados de bovinos condenados por fasciolose no sul do Espírito Santo e encontraram percentuais médios variando de $15,24 \%$ a $28,57 \%$ entre 2006 e 2009, tendo as perdas econômicas devido à condenação de fígados sido consideradas altas.

Alguns trabalhos sugerem que alguns municípios no sul do estado do Espirito Santo, são consideradas regiões endêmicas quanto à presença da F. hepática devido a difusão desses parasitas sem as devidas notificações de sua existência [6]. Desta forma este trabalho, tem por objetivo mapear regiões com potenciais riscos epidemiológicos para a fascíola e verificar padrões geográficos (aglomerados) para a ocorrência da fascíola.
\end{abstract}


A área deste estudo foi representada por 23 municípios do Sul do estado do Espírito Santo. A unidade de análise foram propriedades que tem como objetivo econômico a pecuária bovina, totalizando 115 propriedades, 5 em cada município. $\mathrm{O}$ inquérito epidemiológico nessas propriedades foi feito durante o período compreendido entre 2009 e 2011.

Para a detecção dos aglomerados geográficos, foram utilizadas técnicas tradicionais de análise estatística espacial [5] e de modelagem matemática baseada em Metaheurísticas [3, 4]. As Metaheurísticas são heurísticas genéricas para a solução aproximada de problemas, especialmente os chamados de Otimização Combinatória. Essas técnicas são geralmente aplicadas para solucionar questões de elevada complexidade, por fazer uso de combinações de escolhas aleatórias e conhecimento histórico dos resultados anteriores adquiridos pelo método para se guiarem e realizar buscas pelo espaço de pesquisa em vizinhanças dentro do seu espaço, o que previne paradas prematuras em ótimos locais.

Neste trabalho foi observada a existência de aglomerados geográficos significativos ( $I$ moran $=0,443 ;$-valor $<0,001)$ entre propriedades rurais dos municípios de Jerônimo Monteiro, Muqui e Cachoeiro de Itapemirim. Foi observada também a existência de associação entre propriedades que foram acometidas com o desfecho e a presença do hospedeiro lyminea em áreas potencias de alagamentos ( $\mathrm{p}$-valor $<0,001)$.

Palavras-chave: Metaheurística, Clusters, Fasciola, Epidemiologia Veterinária

\section{Referências}

[1] M.B. Carneiro; C.C. Bernardo; B.R. Avelar; D.M. Donatele; I.V.F. Martins; M.J.S. Pereira. Prevalence of liver condemnation due to bovine fasciolosis in Southern Espírito Santo: temporal distribution and economic losses. Revista Brasileira de Parasitologia Veterinária, Jaboticabal, v.20, n.1, p.49-53, jan.-mar., 2011

[2] M.B. Carneiro, "Estudo Epidemiologico da Fasciola hepatica em Ovinos, Caprinos e Bubalinos em Municípios da Região Sul do Espirito Santo", Dissertação de Mestrado, CCAUFES, 2010.

[3] M.D. Cruz, L.S. Ochi, "O Problema de Clusterização Automática: Um novo método utilizando ILS". Anais do X Congresso Brasileiro de Inteligência Computacional (X CBIC), Fortaleza -CE, 2011.

[4] M.D. Cruz, L.S. Ochi ,"Um Algoritmo Evolutivo com Memória Adaptativa para o Problema de Clusterização Automática". Learning and Nonlinear Models, Volume 8(4), pp. 227-239, 2011.

[5] S. Druck, M.S. Carvalho, G.Câmara, A.M.V. Monteiro, "Análise Espacial de Dados Geograficos", EMBRAPA, DF, 2004.

[6] D.F. Freitas," Análise Espacial do Risco de Fasciolose Bovina no Estado do Espirito Santo por Meio dos Sistemas de Informações Geográficas", Dissertação de Mestrado, CCA-UFES, 2013.

*Bolsista de mestrado Faperj. 